\title{
Application of Advanced Parking Management System Techniques _ a Case Study
}

\author{
Er. Sandeep Singh ${ }^{1}$, Dr. Umesh Sharma ${ }^{2}$ \\ ${ }^{I}$ Research student, Dept. of Civil Engineering (Highway Engineering), PEC University of Technology, Sector- \\ 12, Chandigarh, India \\ ${ }^{2}$ Associate Professor, Dept. of Civil Engineering (Highway Engineering), PEC University of Technology, \\ Sector-12, Chandigarh, India
}

\begin{abstract}
Transportation is the key infrastructure of a country. A country's economy status depends upon how well the country is served by its roads, railways, air ports, ports, pipelines and shipping. The rate at which a country's economy grows is very closely linked to the rate at which the transport sector grows. As road transport gives personal mobility to persons, the vehicle ownership rate has been increasing at a fast rate round the world. Due to increase in car ownership, the problem of parking is becoming more and more acute day by day. Vehicles may be parked on the kerb side but it creates lot of problems like congestion, jams, accidents and also reduces effective road width. Acute shortage of parking facilities is being felt in shopping centres, public places and official complexes. Chandigarh-an internationally acclaimed city is also feeling the pinch of the after effects of the steep vehicular growth. The present work involves the comprehensive study of parking problem in sector-17 (known as Heart of Chandigarh), in which various parameters have been worked out to identify the problem. These parameters have been correlated to workout a long lasting solution based on the advanced parking management system techniques.
\end{abstract}

Keywords: parking, public places, complexity, management, Chandigarh

\section{Introduction}

There is significant and tremendous increase in the demand of parking spaces due to increase of road traffic during the last one decade in small cities, leading to congestion of On-street spaces in official neighbourhoods may give rise to inappropriate parking area in office and shopping mall complex during the peak time of official transactions. The demand also leads to economic, social and environmental losses and with increase in population the problem becomes more critical [15]. As such parking spaces optimization and control has become a real challenge for city transport planners and traffic authority.

This paper is just an example of how big the parking problem is? And what will happen in future? To elaborate the example a study of sector-17, Chandigarh-"The Beautiful City" parking area is done, on the basis of study problem is identified and solutions are also presented.

Parking space problem has been presented by many researchers. The following is a review of some of the recent papers [15].

Caicedo [2] used two different ways to manage space availability information in parking facility within PARC system to reduce search times. Caicedo [10] develops a demand assignment model with the intention of reducing the time and distances involved in finding a parking space. Zhao and Collins [3] Developed an automatic parallel parking algorithm for parking in tight spaces using a novel fuzzy logic controller. Space allocation of parking lots was analyzed by Davis et al. [4] to estimate the supply of parking spaces to potential demand. Using a fuzzy knowledge-based Decision Making, Leephakpreeda [5] presented a car-parking guidance. Arnott and Rowse [6] developed an integrated model for curb side parking and traffic congestion control in a downtown area. Shoup [7] presented a model of how drivers choose between cruising for curb side parking or pay for off-street parking. Teodorovic and Lucic [8] proposed an intelligent parking space inventory system. The system is based on a combination of fuzzy logic and integer programming techniques that would allow making online decisions to accept or reject a new driver's request for parking. Benenson et al., [9] presented an agentbased system that simulates the behaviour of each driver within a spatially explicit model. The system captures, within a no homogeneous road space, the self-organizing and dynamics of a large collective parking agents. Estimation of parking lots footprint across a four state region is presented in [11]. Feng et al., [12] designed a combined trip network for congested road-use pricing and parking pricing which was based on Logic. Using a utility function, combining travel time, search time, waiting time, access time, and parking price, a Profit based parking pricing is formulated for curb parking pricing [13]. Chou et al., [14] presents an intelligent agent system with negotiable parking pricing for optimum car park for the driver. 


\section{Methodology and Analysis Of Parking Study}

[16]:

Whole of the study area is divided as shown in Fig-I and the various studies were conducted such as

A) Special parking lot inventory: The study involved the inspection of the physical attributes of the parking lots and observation of how it was used by parkers. This gave an indication of the adequacy of the lot as the design and operation, it will helpful in improving the lots. Study is basically the Accumulation study.

Study was carried out by getting the layout plan of sector-17 and finding out the dimensions of the concerned lots, with the help of standard formulae the existing parking capacity and the ultimate parking capacities were found out. Data was collected for normal week days, which will be any working day from Monday to Friday, other than holiday. The duration of the study was kept as 12 hours from 10:00 am to 10:00 pm. The time interval was chosen as 1 hour spanning over the whole period of the day. The accumulation data was collected for 3 days for each parking sub-areas and then mean is taken for study.

B) Parking supply: Based on the area available the ultimate parking supply in terms of equivalent car spaces have been worked out for the various parking sub-areas under the study. The existing and ultimate planned parking supply is tabulated in Table I.

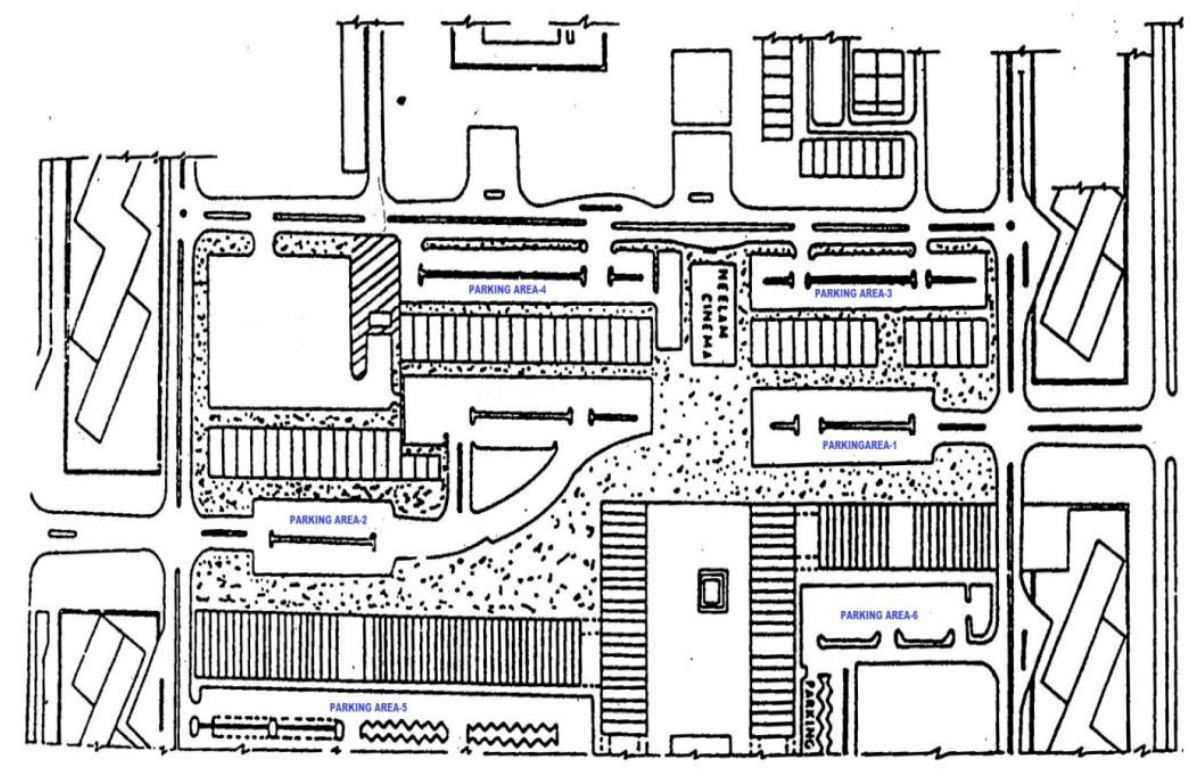

Fig I: Layout plan of main shopping complex area in sector-17

TABLE I

PARKING CAPACITES OF EACH SUB-AREA IN TERMS OF PCU

\begin{tabular}{|c|c|c|c|c|c|c|c|}
\hline S.NO & $\begin{array}{c}\text { PARKIN } \\
\text { G } \\
\text { ANGLES }\end{array}$ & (P1) & (P2) & (P3) & (P3) & (P5) & (P6) \\
\hline 1 & Parallel & 118.5 & 313 & 155 & 274 & 226 & 291.5 \\
\hline 2 & $30^{0}$ & 120.5 & 348 & 165 & 284 & 239 & 308.5 \\
\hline 3 & $45^{0}$ & 154.5 & 469 & 205 & 328 & 338 & 392.5 \\
\hline 4 & $60^{0}$ & 176.5 & 480 & 235 & 360 & 389 & 445.5 \\
\hline 5 & $90^{0}$ & 200.5 & 548 & 278 & 402 & 457 & 515.5 \\
\hline
\end{tabular}

TABLE-II

THE RATIO OF MAXIMUM DEMAND TO PARKING SUPPLY

\begin{tabular}{|c|c|c|c|c|}
\hline S.NO. & SUB-AREAS & $\begin{array}{c}\text { MAXIMUM } \\
\text { DEMAND (PCU) }\end{array}$ & $\begin{array}{c}\text { PARKING } \\
\text { SUPPLY(PCU) }\end{array}$ & $\begin{array}{c}\text { PERCENTAGE } \\
\text { UTILISATION OF } \\
\text { EXISTING } \\
\text { SUPPLY }\end{array}$ \\
\hline 1 & Parking sub-area-1 & 558.5 & 154.5 & 361.48 \\
\hline 2 & Parking sub-area-2 & 777 & 469 & 165.67 \\
\hline 3 & Parking sub-area-3 & 379 & 205 & 184.87 \\
\hline 4 & Parking sub-area-4 & 418.5 & 328 & 127.59 \\
\hline 5 & Parking sub-area-5 & 867 & 338 & 256.50 \\
\hline 6 & Parking sub-area-6 & 637.5 & 392.5 & 162.42 \\
\hline
\end{tabular}


Application Of Advanced Parking Management System Techniques__ A Case Study

From the Table -II questions arise is that if the demand is so much high then where the vehicles get parked? Well the answer is Neutral lane, the surplus vehicles are parked in this lane, made in the centre of path or may be two lane each at the back of correctly parked vehicles, in this lane vehicles are parked in neutral gear so that they can be moved forward or backward to give the way to correctly parked vehicles while it is exiting.

Secondly when a vehicle entered in such a loaded parking and don't get space for parking, there is so much time loss in coming out from parking area. The point is that the vehicle was not parked but was accumulated for a period of time.

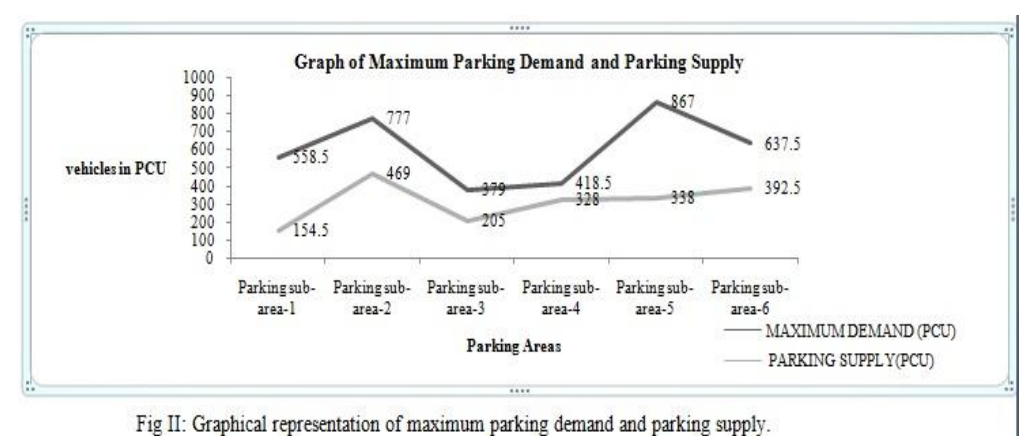

From Fig-II it is clear that the difference between the demand and supply curve is the problem area. So this problem area results not only in Time loss but Fuel loss, Increase in operation cost, Increase in Accidental rate, Agency cost Saving etc also.

Next question arises is that then if this is present situation than what will happen in future? To get answer to this, data of number of vehicles registered in last 10 years was taken [1] and shown as below.

TABLE III

NUMBER OF VEHICLES REGISTERED IN LAST 10 YEARS (SOURCE - [1])

\begin{tabular}{|c|l|c|c|c|c|c|c|c|}
\hline S.No. & \multirow{2}{*}{ Year } & \multirow{2}{*}{ Car/Jeep } & M.Cycle/ & Three & \multirow{2}{*}{ Buses } & Goods & Tractors & \multirow{2}{*}{ Total } \\
& & & Scooter & Wheeler & & Vehicle & & \\
\hline 1 & 2001 & 7643 & 14982 & 36 & 31 & 38 & 9 & $\mathbf{2 2 7 3 9}$ \\
\hline 2 & 2002 & 7969 & 16206 & 74 & 22 & 41 & 6 & $\mathbf{2 4 3 1 8}$ \\
\hline 3 & 2003 & 8471 & 17025 & 101 & 24 & 42 & 4 & $\mathbf{2 5 6 6 7}$ \\
\hline 4 & 2004 & 9555 & 17241 & 96 & 57 & 25 & 5 & $\mathbf{2 6 9 7 9}$ \\
\hline 5 & 2005 & 10265 & 19216 & 86 & 93 & 34 & 3 & $\mathbf{2 9 6 9 7}$ \\
\hline 6 & 2006 & 12893 & 20649 & 75 & 102 & 44 & 14 & $\mathbf{3 3 7 7 7}$ \\
\hline 7 & 2007 & 13812 & 19170 & 72 & 88 & 81 & 33 & $\mathbf{3 3 2 5 6}$ \\
\hline 8 & 2008 & 15129 & 18145 & 128 & 64 & 97 & 14 & $\mathbf{3 3 5 7 7}$ \\
\hline 9 & 2009 & 18861 & 18401 & 451 & 46 & 185 & 21 & $\mathbf{3 7 9 6 7}$ \\
\hline 10 & 2010 & 25194 & 24632 & 649 & 106 & 378 & 32 & $\mathbf{5 0 9 9 1}$ \\
\hline 11 & 2011 & 33294 & 33040 & 1104 & 196 & 604 & 46 & $\mathbf{6 8 2 2 8}$ \\
\hline & TOTAL & 163086 & 218707 & 2872 & 829 & 1569 & 187 & $\mathbf{3 8 7 1 9 6}$ \\
\hline
\end{tabular}

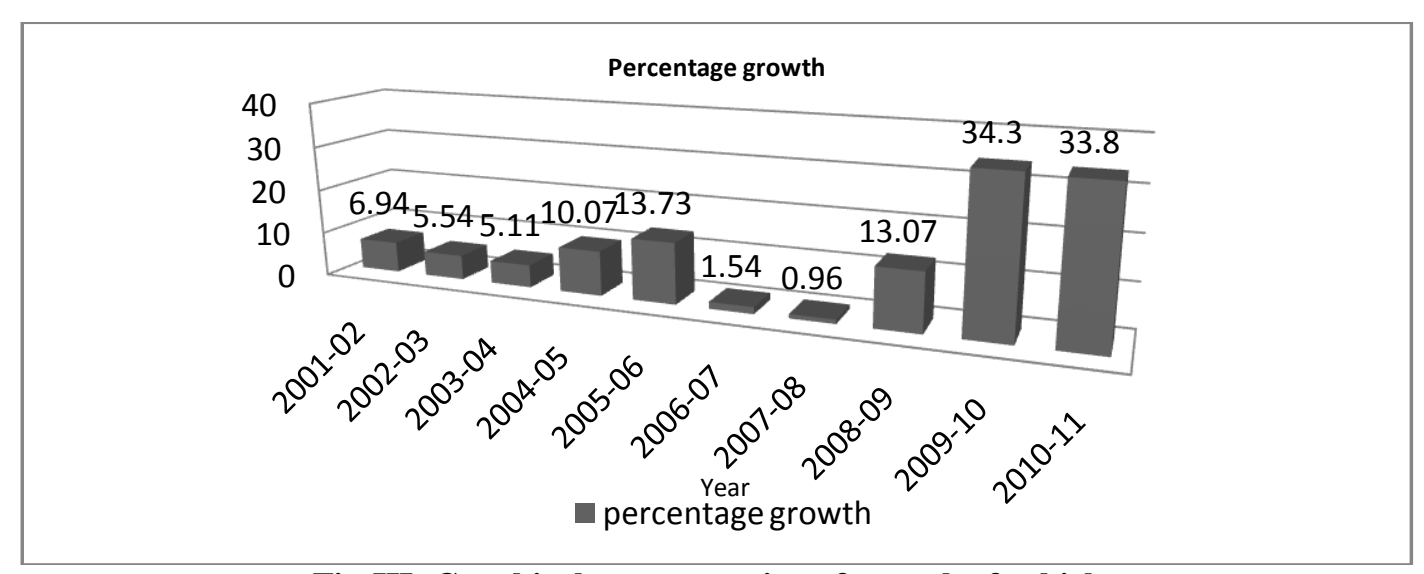

Fig-III: Graphical representation of growth of vehicles

From the above data of last 10 year, it was worked out that the average growth rate of vehicles is 12.50 percent. So in next 7-8 years the demand of parking will be double. 


\section{Conclusion}

In this paper, the authors presented the commute travel effects of parking area in sector-17, Chandigarh, India. The various facts and finding of the study can be listed as under:

A) All the six parking sub-areas are fully packed to their capacity and are in-fact over loaded.

B) The utilization percentage varies from 127.59 to 361.48 percent of all the six subareas. The average utilization factor is 247.54 .

C) At present the demand is surplus as the ratio of parking supply to maximum demand is less than one $(<1)$ for all the six parking sub-areas.

D) The peak accumulation in all the six parking sub-areas is about $12-14$ percent of the total accumulation.

E) The heavy accumulation is in the time period of 12:00 pm to 7:00 pm, and the peak hour is generally 3:00pm $-4: 00 \mathrm{pm}$ or 4:00 pm -5:00 pm in all the cases.

F) The general parking composition is 66.41 percent of four-wheelers, 33.59 percent of two-wheelers, parking of heavy duty vehicles and auto rickshaw is nil all the parking sub-areas.

\section{DISCUSSION AND RECOMMENDATIONS}

The various improvement plans can be formulated in terms of short term and long term planning. Presently, if we integrate the problem of parking in various parking sub-areas into one i.e. superimposing the problem over the whole area, one important factor which comes sharply into focus is the present overall utilization factor of 209.78 percent. This clearly shows that the demand is more than the supply and so, the "mismanagement" of parking space. Keeping the future in mind. The various suggestions and recommendations are presented below:

\section{A) Implementation of ITS (APMS)}

The first step in the management of parking space is the implementation of ITS technology called "Advance Parking Management System".

What will be the advantages of APMS?

I. Proper management of available space.

II. Time saving.

III. Emission/fuel saving.

IV. Accident cost saving.

V. Operating cost saving.

VI. Other.

How APMS will work?

The basic idea of APMS working is shown below in steps:

Step-1: There will be a Electronic Display separately for four wheelers and two wheelers before the entry of parking sub-area showing the Total Capacity, Number of Bays occupied and Number of Bays are vacant. Step-2: There will be electronic toll collection at entry and automatic barrier at the Entry and Exit of parking sub-area. The function of automatic barrier at the Exit is just to slow down the exiting vehicle and to restrict the entry of vehicle from that side.

Step-3: Parking full: If the Electronic Display shows parking full or zero vacant lot, the coming vehicle will not enter in parking sub-area, leave it without wasting time and will go for another parking sub-area. Step-4: Parking Space Available: If the Electronic Display which is located before entry shows vacant parking lots, then the user will move on, enter into parking after

Fig-V: Flow chart showing steps involved

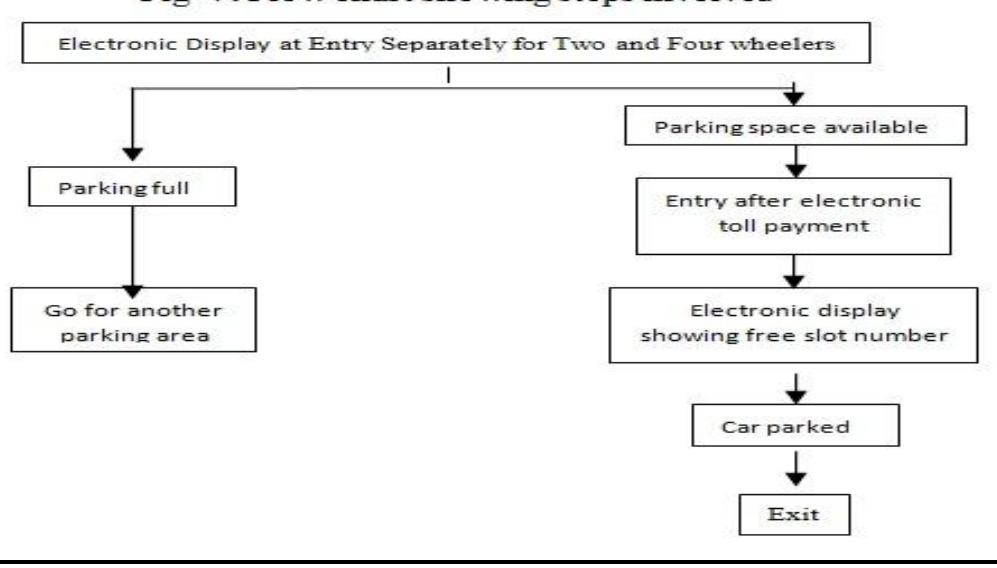


the entry, showing all the parking lots with their numbers and also shows which number lot is vacant. So that the user just go there for parking of vehicle.

Step-5: At the time of Exit vehicle can easily come out without any stop point. Because for quick discharge of vehicles to increase the free spaces in parking sub-area.

B) Parking garages:

As it is known form the studied statistics that the demand is higher than the actual parking space available. So to overcome this problem, there are many spaces available in the periphery of Main Market, Sector-17. These spaces can be used for the construction of Garages either mechanical or ramped. These are desirable in long run. They enabling more cars to be parked per unit height and automation is employed either partial

These garages can also be constructed with in small portions of parking sub-area.The user can be encouraged or forced to use these garages by keeping their toll or fee less than the parking sub-areas. Mainly regular and long term parkers such as showroom owners, employees etc are forced to use these garages.

\section{C) Roof parking:}

Another option is Roof parking, it is the parking which is provided on the roof of building, and this type of parking is provided by joining or connecting the roofs of several buildings of same height and providing separate entry and exit to give safe, easy and efficient access to roof.

As in sector-17 the buildings are of quit big size and are of same height so can be connected and used as roof parking space by providing ramps or lifts to provide accessibility of vehicles to roof. Entry and Exits can be provided separately for each building block separately to avoid wastage of time.

D) Underground parking facility:

In this type of parking the space is constructed to parking under the ground, this is quite expensive construction. Actually in study area there is underground parking facility in some sub-area as in parking subarea-5, but not in use. So, to overcome the problem of shortage of parking space as per demand this kind of space should be properly maintained and optimized to its use.

All the i.e. parking garages, roof parking and underground parking facilities must be provided with APMS system. So that the user can easily get information regarding status of parking area.

\section{References:}

[1] Registration and licensing office, Chandigarh.

[2] Caicedo F. The use of space availability information in "PARC" systems to reduce search times in parking facilities. Transp Res Part C 2009; 17:56-68

[3] Zhao Y, Collins Jr EG. Robust automatic parallel parking in tight spaces via fuzzy logic. Robot Auton Syst 2005; 51:111-27.

[4] Davis AY, Pijanowski BC, Robinson K, Engel B. The environmental and economic costs of sprawling parking lots in the United States. Land Use Policy 2010; 27:255-61.

[5] Leephakpreeda T. Car-parking guidance with fuzzy knowledge based decision making. Build Environ 2007;42:803-9.

[6] Arnott R, Rowse J. Downtown parking in auto city. Reg Sci Urban Econ 2009; 39:1-14.

[7] Shoup DC. Cruising for parking. Transp Policy 2006; 13:479-86.

[8] Teodorovic D, Luc ${ }^{2}$ ic P. Intelligent parking systems. Eur J Oper Res 2006; 175:1666-81.

[9] Benenson I, Martens K, Birfir S. PARKAGENT: an agent-based model of parking in the city. Comput Environ Urban Syst 2008; 32:431-9.

[10] Caicedo F. Real-time parking information management to reduce search time, vehicle displacement and emissions. Transp Res Part D 2010; 15:228-34.

[11] Davisa AY, Pijanowskia BC, Robinsona KD, Kidwellb PB. Estimating parking lot footprints in the Upper Great Lakes Region of the USA. Landscape Urban Plan 2010; 96:68-77.

[12] Feng S, Yan C, Hengxin L, Lianbo D. Class of comprehensive optimization of congested road-use pricing and parking pricing. J Transp Syst Eng Inf Technol 2009; 9:74-9.

[13] Zhenyu M, Yiqiang X, Jun C, Wei W. Optimizing model of curb parking pricing based on parking choice behavior. Syst Eng Inf Technol 2010; 10:99-104.

[14] Chou S, Lin S, Li C. Dynamic parking negotiation and guidance using an agent-based platform. Expert Systems Appl 2008; 35:805-17.

[15] Soumya B, Hameed Al-Q. An intelligent hybrid scheme for optimizing parking space: A Tabu metaphor and rough set based approach, 10 February 2011.

[16] Umesh s and H.C. Bhatia, Chandigarh city centre_A New Look to Parking, 1995, Proc. ICORT-95. 